\title{
PREVALENCE OF SEXUALLY TRANSMITTED DISEASES (STDS) IN PREGNANT WOMEN ATTENDING THE STD CLINIC AT THE INSTITUTE OF SEXUALLY TRANSMITTED DISEASES IN THE ERA OF AIDS
}

\author{
R. Rajesh, V. Sudha
}

1. Associate Professor. Department of Dermatology \& Venereology, IRT Perundurai Medical College,
Perundurai, Tamil Nadu.
2. Professor \& Director. Institute of Venereology, Madras Medical College, Chennai

\section{CORRESPONDING AUTHOR:}

Dr. R. Rajesh,

Associate Professor,

Department of Skin \& STDs,

IRT Perundurai Medical College,

Perundurai-638053, Erode district, Tamilnadu.

E-mail: rajeshderma@gmail.com

\section{ABSTRACT: KEY WORDS: Pregnancy, STDs, HIV / AIDS}

INTRODUCTION: Sexually transmitted diseases (STDs) affecting mankind since antiquity are an important cause of morbidity and mortality worldwide, especially in women and children particularly in resource poor settings of developing world, which are store houses of most of the pathogens causing STDs ${ }^{1,2,3}$.

Women of childbearing age are at particular risk of sequelae from STDs due to the impact of many STDs on their reproductive health. STDs also increase the risk of acquiring and transmitting HIV infection.

The incidence of many STDs has increased during the last two decades, and the number of pregnancies per year is also again increasing, the super imposition of the one factor on the other can be expected to further amplify the effects of STDs on pregnancy and neonatal morbidity.

Infections in pregnancy are common but few causes fetal infection and damage. Particularly urgent is the need to control fetal wastage and congenital abnormalities due to sexually transmitted infections including HIV. Pregnancy is a vulnerable time for women. Hence STDs in the pregnant women are more serious than in the non pregnant women.

When all STDs are considered together, they represent one of the most common medical complications of pregnancy. As the spectrum of STDs has broadened, the medical and social consequences of STD in pregnancy have become more apparent.

STDs pose a constant threat to not only the health of the mother, but also the baby's health. Presence of STDs results in physical and mental agony to the pregnant patient.

The frequent occurrence of multiple STDs co-existing with STD risk factors (non-use of barrier methods, multiple sex partners) may independently adversely affect pregnancy outcome.

Adolescent sexual activity is increasing globally. With the change in social norms, peer pressure and media influences, teenagers are engaging in premarital sex earlier leading to unintended pregnancy and STDs. In general, STD appears to pose a much greater problem in pregnant adolescents than in older pregnant women. Infections of young adult have their most 
serious consequences later in life. Adolescents have miscarriages more often and are partly attributable to STD. Teenage pregnancies remains common in many societies. The incidence of Medical Termination of Pregnancy (MTP) is particularly high among adolescents.

Violence and sexual abuse by men is another aspect where women and girls are the most frequent victims. Pregnancy may also be a sign of ongoing sexual abuse. Meticulous examination should be performed looking carefully for STDs in those cases.

In India, statistics pertaining to STDs are meager. In India, the yearly incidence of STDs is $4-5 \%$, which accounts for 40 million cases per year.

There are about 35 million women in India in the age group of 15-45 years and according to World Bank report, 15\% of healthy life days are lost due to STDs including HIV in those women.

A number of surveys and general beliefs have labelled men as being responsible for the large proportion of ill health suffered by their female partners.

Physiological changes, anatomical in the genital tract, immunological alterations (alterations in host defence mechanisms) in a pregnant female have been postulated to influence the course of STDs, which pose special risk of infection for both mother and fetus.

Diagnosing sexually transmitted infections (STIs) in pregnancy can be difficult because most of them are either asymptomatic or too subtle to recognize clinically as pregnancy modifies the manifestations.

Since a second patient, the fetus, may also be endangered, the cause for screening and treating for asymptomatic genital infectious diseases may be stronger during pregnancy that at other times. Adequate treatment must automatically follow once screening is instituted. Test of cure is not generally advised, but may be considered in STDs during pregnancy.

Study of prevalence of STDs is important to know about their incidence at a particular place and to devise appropriate control measures. Antenatal attenders are a section of population routinely used as a reference point for STD prevalence in the general population of women.

Based on the above facts, the present study was done

1. To determine the prevalence of STDs including HIV infection among the pregnant women attending the STD clinic at the Institute of Sexually Transmitted Diseases, Madras Medical College and Research Institute, Chennai.

2. To study the prevalence of Hepatitis-B surface antigen (HBsAg) among them.

MATERIALS AND METHODS: It is a cross sectional study to find out the prevalence of STDs among pregnant women attending the STD clinic at the Institute of Sexually Transmitted Diseases, Madras Medical College and Research Institute, during the study period of May 1998 to July 1999. A disease with low prevalence may still be a major public health problem. Prevalence data are therefore important for directing and monitoring the impact of public health programmes.

130 consecutive pregnant women at various trimesters who attended the STD clinic at the Institute of Sexually Transmitted Diseases, Madras Medical College and Research Institute, were included in the study.

Majority of the pregnant women were referred from Institute of Obstetrics and Gynaecology, Egmore, Chennai. Also many attended on their own for various genitourinary symptoms. 
Majority of the unmarried pregnant women were referred to be screened for sexually transmitted infections including HIV infection, prior to Medical Termination of Pregnancy (MTP).

A well structured, pre-tested proforma was prepared and used for the study. It consisted of various informations including their age, socio-economic status, sexual history and obstetric history apart from detailed clinical history. Pregnant women were screened for STDs and a provisional diagnosis was made. Investigations were accordingly to confirm the diagnosis.

Special investigations done for the study were:

A. Vaginal discharge for culture of Candida species (spp) in Sabouraud's agar medium.

B. Blood for HBs Ag by Enzyme Linked ImmunoSorbent Assay (ELISA).

\section{A. Vaginal discharge for culture of Candida species (spp) in Sabouraud's agar medium \\ Sabouraud's medium is the commonest fungal cultural media used.}

It consists of ingredients like glucose, cycloheximide, agar etc. Sterile vaginal swabs were used for taking specimens. Cultures were incubated at room temperature $\left(22^{\circ} \mathrm{c}\right)$ for 2 weeks.

Identification was based on the colony appearance (creamy, white, mucoid) and the morphology of the fungus by microscopy. The method of identifying candida albicans was based on its ability to form germ tubes with in two hours when incubated in human serum at $37^{\circ} \mathrm{C}$.

\section{B. Blood for HBs Ag by Enzyme Linked ImmunoSorbent Assay (ELISA)}

Anti-HBs antibody is bound to either a plastic bead or plate. If HBs Ag is present in the serum, after the addition of enzyme, colour change occurs which can be measured spectrophotometrically. The development of yellow colour denotes a positive test.

RESULTS: In this study, 130 pregnant women were examined and the following results were obtained.

\section{TABLE NO 1 AGE DISTRIBUTION OF PREGNANT WOMEN IN THE STUDY GROUP (n=130)}

\begin{tabular}{|c|c|c|}
\hline Age groups in years & Total No. & Percentage (\%) \\
\hline $15-19$ & 24 & 18.5 \\
\hline $20-24$ & 72 & 55.4 \\
\hline $25-29$ & 25 & 19.2 \\
\hline $30-34$ & 8 & 6.2 \\
\hline $35-39$ & 1 & 0.8 \\
\hline
\end{tabular}

Majority of the pregnant women were in the age group of 20-24 (55.4\%). Majority of the pregnant women belonged to lower socio-economic strata.

MARITAL STATUS OF THE PREGNANT WOMEN IN THE STUDY GROUP $(n=130)$

Majority of the pregnant women were married ( $n=100,76.9 \%)$

In women, who were single $(n=30,23.1 \%)$, majority were deserted by their known partner after knowing about the present pregnancy $(n=25,83.3 \%)$ ), other forming the group were kept mistress $(n=3,10 \%)$ and commercial sex workers $(n=2,6.6 \%)$. 


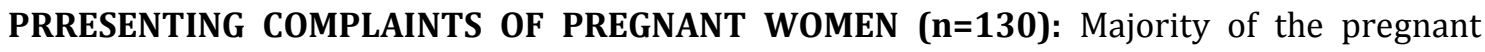
women had visited the STD clinic for check up $9 n=62,47.7 \%)$. Genital discharge and genital sore were the most common presenting complaints in $36(27.7 \%)$ and 17 (13.1\%) patients respectively, followed by itching in the genitalia in $15(11.5 \%)$ and growth in genitalia in 10 (7.7\%) patients. Some pregnant women also had other symptoms like burning micturition $(\mathrm{n}=6$, $4.6 \%)$, lower abdominal pain ( $n=6,4.6 \%)$, fever $n=3,2.3 \%)$, cough $(n=2,1.5 \%)$, loose stools $(n=2,1.5 \%)$, loss of weight $(n=2,1.5 \%)$, frequency of micturition $(n=2,1.5 \%)$, swelling of genitalia $(n=2,1.5 \%)$, loss of appetite $(n=1,0.8 \%)$, and dysuria $(n=1,0.8 \%)$.

When married pregnant women were interviewed for this study, around $4 \%$ gave history of $(\mathrm{H} / \mathrm{O})$ extramarital contact $(\mathrm{n}=4)$ and $2 \%$ gave $\mathrm{H} / \mathrm{O}$ premarital contact $(\mathrm{n}=2)$. One women $(1 \%)$ gave $\mathrm{H} / \mathrm{O}$ both pre and extra marital contacts.

Among unmarried pregnant women, 25 women who were otherwise single, gave H/o contact with a known partner (83.3\%). Two women (6.7\%) who were commercial sex workers gave $\mathrm{H} / \mathrm{O}$ contact with multiple males. Three women $(10 \%)$ who were kept mistress for a known partner denied $\mathrm{H} / \mathrm{O}$ exposure out side.

Among the 11 pregnant women (8.5\%), who gave past H/O STD, 7 had genital ulcer (63.6\%), 3 had genital discharge (27.3\%). One had documented history of warts $(9.1 \%)$. The rest of the pregnant women $(91.5 \%, \mathrm{n}=119)$ denied any history of previous STDs.

Bad obstetric history was found in 34 patients (26.2\%) out of 130 pregnant women screened in the study. Majority of them had spontaneous abortions ( $n=20,58.8 \%)$, followed by still births $(n=8,23.5 \%)$, and neonatal deaths $(n=3,8.8 \%)$ had both spontaneous abortions and still births.

Cervical erosion was the most common clinical sign seen in 38 (29.2\%) pregnant women. Soddening of the vulva was the next most common sign seen in 25 (19.2\%) pregnant women, followed by genital ulcer in 18 patients (13.8\%). Anogenital wart were noted in 10 (7.7\%). They were distributed over labia majora, labia minora, fouhette and perianal region. One women had cervical wart in addition in addition to ano genital warts. Arthralgia and osteologia were seen in $2(1.5 \%)$ patients. Among the pregnant women, cervical nodes were enlarged in 6 (4.6\%), epitrochlear in $4(3.1 \%)$ and occipital nodes in $2(1.5 \%)$. Uretheral caruncle was seen in 2 pregnant women $(1.5 \%)$.

\section{TABLE NO 2 NATURE OF THE GENITAL DISCHARGE AMONG THE STUDY GROUP $(n=130)$}

\begin{tabular}{|l|c|c|}
\hline Nature of the discharge & Total No. & Percentage (\%) \\
\hline Mucopurulent & 52 & 40 \\
\hline Mucoid & 48 & 36.9 \\
\hline Curdy white & 26 & 20 \\
\hline Frothy & 3 & 2.3 \\
\hline Serosanguinous & 1 & 0.8 \\
\hline
\end{tabular}

Majority of the pregnant women had Mucopurulent discharge $(n=52,40 \%)$ 
TABLE NO 3 RESULTS OF INVESTIGATIONS IN THE STUDY GROUP $(n=130)$

\begin{tabular}{|l|c|c|}
\hline \multicolumn{1}{|c|}{ Investigations } & $\begin{array}{c}\text { Positive results } \\
\text { (Total No.) }\end{array}$ & Percentage (\%) \\
\hline Culture for candida spp. & 62 & 47.7 \\
\hline Gram stain for candida & 39 & 30 \\
\hline KOH mount for candida & 28 & 21.5 \\
\hline Wet film for Trichomonas vaginalis & 14 & 10.8 \\
\hline Gram stain for clue cells & 3 & 2.3 \\
\hline Urine culture (routine) & 3 & 2.3 \\
\hline
\end{tabular}

TABLE NO 4 ORGANISIMS ISOLATED IN URINE CULTURE AMONG THE STUDY GROUP $(n=3)$

\begin{tabular}{|l|l|l|}
\hline Organism & Total No. & Percentage (\%) \\
\hline Escherichia coli & 2 & 66.7 \\
\hline Staphylococcus aureus & 1 & 33.3 \\
\hline
\end{tabular}

Endocervical and urethral smear for gonococcus (Gram stain), and endocervical culture for gonococcus were negative in all pregnant women.

Vaginal discharge for the culture of candida species in Sabouraud's dextrose agar medium revealed growth in 62 cases (47.7\%). Candida albicans was the most frequently isolated candida species in 53 cases $(85.5 \%)$.

TABLE NO 5 VDRL REACTIVITY / TPHA

\begin{tabular}{|l|l|l|}
\hline Serological test & $\begin{array}{l}\text { Patients with } \\
\text { Reactive VDRL/TPHA }\end{array}$ & Percentage (\%) \\
\hline VDRL/TPHA & 33 & 25.4 \\
\hline
\end{tabular}

Blood VDRL / TPHA were reactive in 33 (25.4\%) patients. Blood VDRL / TPHA were nonreactive in $97(74.6 \%)$ patients.

TABLE NO 6 PREVALENCE OF HBs Ag

\begin{tabular}{|c|c|c|}
\hline Serological test & Patients positive for HBs Ag & Percentage (\%) \\
\hline HBs Ag & 23 & 17.7 \\
\hline
\end{tabular}

ELISA test for Hepatitis -B surface antigen (HBs Ag) was positive in 23 patients (17.7\%). It was negative in 107 patients $(82.3 \%)$

TABLE NO 7 PREVALENCE OF HIV INFECTION

\begin{tabular}{|c|c|c|}
\hline Serological test & Total No. of patients positive for HIV antibodies & Percentage (\%) \\
\hline HIV & 8 & 6.2 \\
\hline
\end{tabular}

Out of the 130 pregnant women screened for HIV antibodies, 8 women $6.2 \%$ were found to be seropositive. 122 women (93.8\%) had no HIV antibodies in their serum by ELISA test. 
TABLE NO 8 DISTRIBUTION OF INFECTIONS AMONG PREGNANT WOMEN

\begin{tabular}{|l|c|c|}
\hline \multicolumn{1}{|c|}{ Infections } & Total No. & Percentage (\%) \\
\hline Vulvovaginal Candidiasis & 62 & 47.7 \\
\hline Syphilis & 33 & 25.4 \\
\hline Hepatitis-B & 23 & 17.7 \\
\hline Trichomoniasis & 14 & 10.8 \\
\hline Genital herpes & 13 & 10 \\
\hline Genital warts & 10 & 7.7 \\
\hline HIV & 8 & 6.2 \\
\hline Non-gonococcal urethritis & 6 & 4.6 \\
\hline Bacterial vaginosis & 3 & 2.3 \\
\hline Non-specific genital ulcer & 2 & 1.5 \\
\hline Chancroid & 1 & 0.8 \\
\hline Molluscum contagiosum & 1 & 0.8 \\
\hline scabies & 1 & 0.8 \\
\hline
\end{tabular}

Out of 33 patients with syphilis, one had primary syphilis (3\%), five had secondary syphilis $(15.2 \%)$ and 27 had early latent syphilis $(81.8 \%)$

TABLE NO 9 COMPARISION OF INFECTION AMONG MARRIED PREGNANT WOMEN $(n=100)$ AND UNMARRIED PREGNANT WOMEN $(n=30)$

\begin{tabular}{|c|c|c|c|c|}
\hline \multirow{2}{*}{ Infections } & \multicolumn{2}{|c|}{ Married (n=100) } & \multicolumn{2}{c|}{ Unmarried (n=30) } \\
\cline { 2 - 5 } & Total No. & $\mathbf{9}$ & Total No. & $\mathbf{\%}$ \\
\hline Vulvovaginal Candidiasis & 48 & 48 & 14 & 46.7 \\
\hline Syphilis & 32 & 32 & 1 & 3.3 \\
\hline Hepatitis-B & 17 & 17 & 6 & 20 \\
\hline Genital herpes & 13 & 13 & 0 & 0 \\
\hline Trichomoniasis & 11 & 11 & 3 & 10 \\
\hline Genital warts & 10 & 10 & 0 & 0 \\
\hline HIV & 6 & 6 & 2 & 6.7 \\
\hline Non-gonococcal urethritis & 5 & 5 & 1 & 3.3 \\
\hline Bacterial vaginosis & 2 & 2 & 1 & 3.3 \\
\hline Chancroid & 1 & 1 & 0 & 0 \\
\hline Non-specific genital ulcer & 1 & 1 & 1 & 3.3 \\
\hline Molluscum contagiosum & 1 & 1 & 0 & 0 \\
\hline scabies & 0 & 0 & 1 & 3.3 \\
\hline
\end{tabular}

TABLE NO 10 DISTRIBUTION OF INFECTIONS AMONG HIV-POSITIVE PREGNANT WOMEN $(n=8)$

\begin{tabular}{|c|c|c|}
\hline Infection & Total No. & Percentage (\%) \\
\hline Vulvovaginal Candidiasis & 6 & 75 \\
\hline
\end{tabular}




\begin{tabular}{|c|c|c|}
\hline Genital herpes & 2 & 25 \\
\hline Hepatitis-B & 2 & 25 \\
\hline Syphilis (Early latent) & 1 & 12.5 \\
\hline Genital warts & 1 & 12.5 \\
\hline Non-gonococcal urethritis & 1 & 12.5 \\
\hline scabies & 1 & 12.5 \\
\hline
\end{tabular}

Among the 8 HIV-positive pregnant women (6.2\%) examined and investigated, all had single or multiple infections. Two most important STDs met with in these patients were genital herpes in 2(25\%) and Hepatitis-B in 2(25\%).

\section{TABLE NO 11 CONCOMITANT INFECTIONS IN THE STUDY GROUP OF PREGNANT WOMEN $(n=130)$}

\begin{tabular}{|l|c|c|}
\hline \multicolumn{1}{|c|}{ Infections } & Total No. & $\begin{array}{c}\text { Percentage } \\
\text { (\%) }\end{array}$ \\
\hline Candidiasis + Hepatitis-B & 8 & 6.2 \\
\hline Candidiasis + Genital herpes & 8 & 6.2 \\
\hline Candidiasis + HIV & 6 & 4.6 \\
\hline Candidiasis + Genital warts & 6 & 4.6 \\
\hline Candidiasis + Non-gonococcal urethritis & 1 & 0.8 \\
\hline Candidiasis + Molluscum contagiosum & 1 & 0.8 \\
\hline Candidiasis + Non-specific genital ulcer & 1 & 0.8 \\
\hline Syphilis + Hepatitis-B & 11 & 8.5 \\
\hline Syphilis + Candidiasis & 10 & 7.7 \\
\hline Syphilis + Trichomoniasis & 2 & 1.5 \\
\hline Syphilis + Non-gonococcal urethritis & 2 & 1.5 \\
\hline Syphilis + Genital herpes & 1 & 0.8 \\
\hline Syphilis + HIV & 1 & 0.8 \\
\hline Trichomoniasis + Candidiasis & 7 & 5.4 \\
\hline Trichomoniasis + Hepatitis-B & 1 & 0.8 \\
\hline Trichomoniasis + Genital herpes & 1 & 0.8 \\
\hline Trichomoniasis + Non-gonococcal urethritis & 1 & 0.8 \\
\hline Non-gonococcal urethritis + HIV & 1 & 0.8 \\
\hline Non-gonococcal urethritis + Hepatitis-B & 1.5 \\
\hline Non-gonococcal urethritis + Genital warts & 1 & 0.8 \\
\hline Genital herpes + HIV & 1 & \\
\hline
\end{tabular}


CASE STUDY (PREVALENCE)

\begin{tabular}{|l|c|c|}
\hline Genital warts + HIV & 1 & 0.8 \\
\hline Genital warts + Hepatitis-B & 1 & 0.8 \\
\hline HIV + Hepatitis-B & 2 & 1.5 \\
\hline HIV + Scabies & 1 & 0.8 \\
\hline
\end{tabular}

TABLE NO 12 DISTRIBUTION OF INFECTIONS AMONG HUSBANDS $(n=82)$ OF MARRIED PREGNANT WOMEN

\begin{tabular}{|l|c|c|}
\hline \multicolumn{1}{|c|}{ Infections } & Total No. & Percentage (\%) \\
\hline Syphilis & 26 & 31.7 \\
\hline Hepatitis-B & 10 & 12.2 \\
\hline Genital herpes & 5 & 6.1 \\
\hline HIV & 5 & 6.1 \\
\hline Candidial Balanitis & 4 & 4.9 \\
\hline Non-gonococcal urethritis & 4 & 4.9 \\
\hline Anogenital warts & 3 & 3.7 \\
\hline Non-specific genital ulcer & 1 & 1.2 \\
\hline Chancroid & 1 & 1.2 \\
\hline Gonorrhoea & 1 & 1.2 \\
\hline
\end{tabular}

Among the husbands ( $\mathrm{n}=82$ ) examined and investigated, forty-five (54.9\%) had single or multiple infections. Among those who were affected with syphilis $(\mathrm{n}=26), 2$ had primary syphilis (7.7\%), three had secondary syphilis (11.5\%), 20 had early latent syphilis (76.9\%) and one had late latent syphilis (3.8\%).

DISCUSSION: In this study, majority of the pregnant women were in the age group of 20-24, followed by 25-29. a significant number of pregnant women were below 19 years. This study has confirmed that adolescent sexual activity has increased resulting in rise in unintended pregnancy rate. The load of STDs in this group of community is a reflection of the control programmes prevailing in that locality. Due to early initiation of sexual activity, they are more prone for STDs including HIV. As they often resort to MTP, services offered to them should include STD check up and knowledge about contraception. These teenage pregnancies often limit future educational economical opportunities for mother, father and child. By helping adolescents to delay their sexual debut, we can offer hope to the greatest number of teens.

Majority of the pregnant women belonged to lower socio-economic strata. Lower socioeconomic status often co-exist with poor nutritional status of pregnant women which in turn affect the course of the disease and their obstetrics outcomes.

Majority of the pregnant women in this study were married. A considerable number of pregnant women were unmarried. They form an important risk group for acquiring STDs including HIV infection as they are exposed to high-risk sexual behaviour.

Majority of the pregnant women had visited the STD outpatient department for checkup. Most of them were referred cases. A good number of pregnant women [resented with various genitourinary symptoms on their own along with their partners. This increase in number of selfreferral by these women could be as a result of campaigns conducted for generating awareness about STDs including HIV infection. 
Nearly half of the pregnant women reported only for checkup. However on clinical examination and completion of investigations, it was found that $115(88.5 \%)$ pregnant women were found to be suffering from one or other infections. This shows that majority of the pregnant women were asymptomatic. Genital infections often remain unnoticed during pregnancy as their signs and symptoms may be seen as part of the normal discomfort of pregnancy. The asymptomatic nature of infections in females and their frequent consultation in gynaecological clinics instead of STD clinics my have been responsible for a low prevalence of STD reported in women. Hence, it is important to screen and treat such asymptomatic cases with obligatory partner therapy to prevent STD leading to unwanted consequences. This was in accordance with data published in earlier studies.

Among the asymptomatic pregnant women $(n=62), 19$ were found to be affected with early latent syphilis, 16 with Hepatitis-B, 3 with HIV. One had both HIV and syphilis, one had both HIV and Hepatitis-b. the significance of this is that pregnant women may not be aware of the silent clinical states of syphilis , Hepatitis-B and HIV. This may lead to delay in detection in initial stages, so that effective interventions can be done. Genital discharge, genital sore and itching in genitalia were the most common symptoms noticed among the study group.

Majority of the married pregnant women denied history of premarital or extramarital contacts. This stresses the fact that innocent housewives were infected by their promiscuous husbands. Their unborn and new born children were also at risk.

Majority of the unmarried pregnant women gave history of exposure with only one male partner. None of the women in the study group or their partner were found to practice safersex. This makes them prone to unintended pregnancy and sexually transmitted infections (STIs). If these STIs are left undetected and untreated during pregnancy, they produce reproductive ill health at a later date.

Genital ulcer was the commonest among previous STDs noted. Genital infections, particularly ulcerative diseases are associated with sexual transmission of HIV. We also noted increased rate of recurrence of genital herpes during pregnancy, similar to other observers. During pregnancy, the link to other partners or the partners of their sexual partner is often either ignored or not even made, thus increasing the likelihood of reinfection of curative treatment.

Bad obstetric history (BOH) was noted in a significant proportion of pregnant women. Majority of them had spontaneous abortion in the past, followed by still births and neonatal death. Among these women $(n=34)$, majority have found to have syphilis $(n=14,41,2 \%)$. The other STDs noted were Trichomoniasis ( $\mathrm{n}=3,8.8 \%)$, Hepatitis-B $(\mathrm{n}=3,8.8 \%)$, Genital herpes $(n=2,5.9 \%)$, HIV $(n=1,2.9 \%)$ and bacterial vaginosis $(n=1,2.9 \%)$.the remaining pregnant women were not found to have any infections. Hence it is necessary to screen all women with BOH (a significant risk factor) for presence or absence of STIs.

In the study group, cervical erosion, saddening of vulva, genital ulcer and genital warts were the important clinical signs noted. Erosion of the cervix was seen in nearly one third $(n=38,29.2 \%)$ of pregnant women. Erosion or cervical ectopy enhance the entry of a variety of pathogenic agents (E.g. HIV, HPV, HSV, Trichomonas, Chlamydia etc).

Generalized Lymphadenopathy is an important sign of secondary syphilis and HIV disease. Among pregnant women $4.6 \%$ had generalized Lymphadenopathy. These women were found to have secondary syphilis or HIV infection.

Generalized skin rash is a characteristic feature of syphilis in its secondary stage. Pregnant women suffering from secondary syphilis had generalized skin rashes. Papulo- 
squamous type of rashes $(n=2)$ were seen more commonly than maculopapular type $(n=1)$. Moist, grayish white, flat topped papules (Condylomata lata) which are highly infective in nature were seen in four pregnant women.

Signs of HIV infection like loss of weight, oral candidiasis, oral hairy leukoplakia were noted in a seropositive pregnant women. In the study group,8cases were found to be HIV positive. Absence of signs of HIV infection may be due to early detection of hidden cases. Hence to detect early cases, the primary prevention services (counseling on HIV / STI / RTI) should be offered to pregnant women in the OPD. The antenatal clinics should be utilized effectively for imparting education to pregnant women about HIV / AIDS.

In this study, Mucopurulent vaginal discharge was commonly seen. Vaginal discharge apart from vaginal infections may also be caused by Mucopurulent cervicitis, so it is essential to examine cervix of all patients with Vulvovaginal complaints using speculum. Vaginal discharge is definitely an important co-factor for STD/HIV transmission.

Patients with Trichomonas vaginalis $(n=14)$ had predominantly mucopurulent discharge and the typical frothy discharge of Trichomoniasis was seen only in three.

The usual description of discharge in Vulvovaginal candidiasis is curdy white and adherent. In this study, only $20 \%$ of the pregnant women had the above said clinical sign. Majority of these patients had no symptoms whole the rest complained of itching in genitalia. The clinical presentation is similar in both HIV infected and seronegative pregnant women although severity of symptoms were noted in the former.

Three patients $(2.3 \%)$ had Bacterial vaginosis (BV) and their genital discharge was mucoid in nature. Prevalence of BV in our study was low compared to an American study, which quotes prevalence of $15-20 \%$. Wet mount, Gram staining and diagnostic criteria established by Amsel et al should be stringently followed not to miss cases of BV as it is associated with bad obstetric outcomes. Routine screening and treatment should become the standard of practice.

Serosanguinous discharge was noted in a pregnant woman with extensive genital herpes. A pregnant women with severe Genital herpes presented with retention of urine in the third trimester. Culture from the endocervical canal for gonococcus was negative in all the study subjects. Non-gonococcal urethritis was seen in six pregnant women, of which E.Coli was the commonly seen isolate $(n=2)$.

The prevalence of VDRL/TPHA reactivity was $25.4 \%$. early latent syphilis $(n=27)$ was the stage of luetic disease seen in this study followed by secondary syphilis $(n=5)$ and primary chancre $(n=1)$. The prevalence rate of syphilis in developing countries is between $3-19 \%$. In a Calcutta study, $8 \%$ of antenatal attendants were VDRL test strongly reactive. Our observations stress for continuous examination of all antenatal mothers for VDRL test routinely. This increase in VDRL test routinely. This increase in VDRL reactivity in this study could be due to referral of high risk pregnant women to the STD clinic. Thus in this study, syphilis was the major STD. it confirms the fact that syphilis still remain a common complication of pregnancy, despite availability of cheep, accurate diagnostic tests and sensitivity of Treponema pallidum to penicillin. We have not encountered any biologically false positive VDRL reaction in our study group of 130 pregnant women. Prenatal care should begin with a STS and end with a STS. In patients at high risk, there should be additional intermediate testing at the beginning of the third trimester. We advocate that expectant mothers should be treated when non-treponemal and treponemal tests are reactive if on through evaluation the cause of a possible false positive result cannot be ensured. 
The prevalence of HBs Ag in the study group was $17.7 \%$, which is on par with other Indian studies. This high prevalence data could be due to high-risk population screened. All pregnant women should be screened at the first prenatal visit for HBs Ag. Sexual partner and children of HBs Ag positive mothers should be offered testing and vaccination.

In this study group, prevalence of HIV was $6.2 \%$, which is relatively higher than some Indian studies. To detect HIV positive pregnant women earlier to prevent MTCT, programmes which offer active group education, counseling of women and their husbands, HIV testing, cost free anti viral therapy, informative education about infant feeding, modes of delivery and MTP for all the pregnant women participants should be implemented across the country for the prevention and control of HIV pandemic.

The prevalence of Genital herpes in the study population was $10 \%$. Most of these cases were due to recurrences of HSV infection especially in third trimester. Low prevalence of genital herpes is comparable with other studies. It might be due to self resolving short course of the disease and overlooking of the disease during diagnosis. Serology helps in actual determination of the prevalence of HSV infection than clinical examination alone.

The prevalence of Genital warts in the group of pregnant women studied was $7.7 \%$. this was almost comparable to the existing data available. Extensive huge, Anogenital warts were noted in HIV positive pregnant women. Only one on the study had pervious history of Condyloma acuminata.

Prevalence of Trichomoniasis in the study population was $10.8 \%$. this corroborates with the reported prevalence data. Trichomonas vaginalis was a significant contributor in 14 out of 115 pregnant STD cases. Further out of 14 Trichomonas vaginalis, 7 cases were associated with Candida Spp, one each with Hepatitis-B, HSV and non-gonococcal urethritis. Trichomoniasis itself is consider to cause NGU. This study highlights the importance of T.Vaginalis as an important indicator for other etiological STD agents.

About $50 \%$ of the pregnant women had genital candidiasis. Candida Spp was isolated more with culture method (47.7\%) than $\mathrm{KOH}$ mount $(21.5 \%)$ and Gram stain (30\%). Hence to detect VVC in pregnancy, culture is the gold standard. This study confirmed the aspects that Vulvovaginal candidiasis is more common in pregnancy and was the most common condition among HIV positive pregnant women $(n=6)$. Most of the sero positive women with VVC were symptomatic. Oral thrush was noted in seropositive women in addition to VVC. Recurrent VVC reported in HIV positive women is not encountered in our study. Vulvovaginal candidiasis coexisted with many other STDs in this study. Species isolation was done using germ tube test.

Albicans species (85.5\%) predominated this study. Non-albicans Spp formed a sizeable percentage $(14.5 \%)$ among the isolated species. All patients with symptomatic genital candidiasis had positive isolates. Speciation of candida (albicans Vs non-albicans) which is gaining importance in the era of HIV and antifungal drugs resistance was done as the clinical manifestations of both are clinically indistinguishable, percentage of non-albicans Spp is rising dramatically and some of non-albicans Spp, C.albicans Spp in the presence of HIV are resistant are less susceptible to azole therapy.

Our study confirms the fact there is an increased frequency of other candida species isolated in recent times, although $\mathrm{C}$. albicans is still responsible for majority of isolates.

The important sexually transmitted infections (STIs) found in married pregnant women(n=100) were syphilis(32\%) Hepatitis-B(17\%), Genital herpes(13\%), Trichomoniasis(11\%), Genital warts(10\%) and HIV(6\%). 
The most important infections found after screening of unmarried women $(n=30)$ were Hepatitis-B(20\%), Trichomoniasis(10\%), and HIV(6.7\%). The problems of STIs, non-marital pregnancy and their consequences are two of the most significant issues faced by society today. Individuals in this group being adventurous and immature with a considerable inquisitiveness for sex and lack of healthy recreation was probably responsible for this high prevalence.

It could be noted from this study that the prevalence data of Hepatitis-B, HIV, Trichomoniasis and Candidiasis were almost the same in married and unmarried pregnant women.

In our study, Candidiasis and syphilis were the predominant infections in pregnant women. This in conformity with the studies done by Sujay Khandpur et al. infections like Nonspecific genital ulcers(n-2), Chancroid(n=1), Molluscum Contagiosum(n-1), Scabies(n=1) were also seen in this study group.

Among the HIV-positive women in this study group, viral STDs [Hepatitis-B 9(n=2) / Genital herpes(n+2) / Warts(n=2)] were found to be more common than bacterial STDs, which is consistent with other studies. High index of suspicion is required to detect viral STDs in HIV such as HSV as it manifests atypically. Early diagnosis and treatment of viral infections positively affects the HIV progression and decrease the risk of MTCT.

Uncontrolled studies conform with our study which reports increased prevalence and severity of VVC in HIV seropositive women. Hence it is suggested that HIV serologic testing may be done in women with recurrent symptoms. As our number of seropositive pregnant women were less, prevalence of other STDs cannot be compared with available data.

Co-infection (mixed infections) with two or more organisms occurred in significant percentage of study group. Hepatitis-B and syphilis co-existed in eleven (8.5\%) cases. Our observation agrees with that of other workers that HBs Ag is seen more frequently in patients with positive syphilis serology. Occurrence of more than one STD noted in this study must make any clinician suspicious of possible concomitant STD pathogens.

STD rate was high $(n=82,54.9 \%)$ among the husbands of married pregnant women (n100) screened. Commonest STD among them was again syphilis. These heterosexual high-risk males are engaged in extramarital contacts with low condom usage with CSWs. Educational and behavioral interventions are urgently needed to help them to avoid HIV and other STDs. Contact slip practice should be stringently followed to enable patients to bring partners for management when so advised.

CONCLUSION: This study revealed that majority of the pregnant women attending the STD clinic was found to suffer from atleast one STD. this study also revealed the high prevalence of syphilis and Hepatitis-B. a larger proportion of them were asymptomatic. Hence, all pregnant women have tobe screened for Syphilis (Blood VDRL) and Hepatitis-B (HBs Ag) to prevent vertical transmission.

The prevalence of HIV infection among the study group was high. Hence it is suggested that all pregnant women should be counseled and encouraged to be tested for HIV.

An important STD risk factor noticed in this study was promiscuity among husbands of pregnant women. Health education regarding transmission of STDs, safer sex and counseling should be made available to them. Prompt treatment of infected patients and their partner(s) by early detection will prevent further transmission. It will also minimise the severity of long term sequelae. The large number of pregnant women with an STD provides an important opportunity to reduce the reservoir of infection in the broader community. Hence systematic screening of 
Sexually Transmitted Infections (STIs) in pregnancy combined with adequate treatment and follow-up will reduce the risk of maternal, fetal and neonatal adverse consequences. Appropriate antenatal, intrapartum, and postnatal care should be provided.

Unmarried pregnant women who attended the STD clinic in this study prior to Medical Termination of Pregnancy (MTP) had or have an increased risk of acquiring STDs. Counseling services, knowledge regarding use of contraceptives and provision of STD care should be made available to them. The health care professionals must educate not only about the STDs and their consequences but also about life styles and behavior changes. Our role should be to encourage responsible sexual behavior, not to moralise about it. Hence this study highlights the need for specific intervention strategies to tackle these problems like sex education in school to prevent unintended pregnancy and STDs.

To conclude, there is an urgent need to mount effective, rational and feasible intervention programmes to combat the HIV/STD pandemic, making optimum use of the existing health and social welfare services

\section{REFERENCES}

1. Gina Dallabetta, Marie laga, Peter lamptey,1996. "Control of Sexually Transmitted Diseases".AIDSCAP/Family health International.U.S.A.p169-186.

2. M.Passey,C.S.Mgone,S.Lupiwa.1998, "Screening for STDs in rural women in Papua new Guinea". Bulletin of WHO,76(4) : 401-411.

3. Bourgeois A,D Henzel,G Malonga -Mouelet.1998. "Clinical algorithms for the screening of pregnant women for STDs in Libreville, Gabon-which alternatives -Sexually Transmitted infections : $74: 35-39$.

4. Dan Hellberg, Irene Mogilevkina. 1996 April. "Sexually transmitted diseases and Gynaecologic symptoms and signs in women with a history of induced abortion".Sexually Transmitted Diseases. Vol.26.No.4.

5. Katherine A,Martens.1994 Feb."Sexually Transmitted and genital tract infections during pregnancy". Pregnant patient Emergency medicine - Clinics of North America.Vol.12.No.1.

6. Taha E Taha, Guna A Dallabetta.1998. "Trends of HIV-1 and Sexually Transmitted Diseases among pregnant and postpartum women in urban Malawi" -AIDS 12:197-203.

7. Catherine S Peckham. 1996 August. "Infection in the Fetus" - Medicine International : 6168.

8. Juliet Heller.1998 Sep - Oct. "Violence and Reproductive health" - World health $51^{\text {st }}$ year No.5.

9. Krishna Menon, Devi, Bhaskar Rao.1991. "Postgraduates Obstetrics and Gynaecology" - 4th edition. Orient Longman Publishers, p-367.

10. Cunningham, Mac Donald, Gant Laveno. Williams Obstetrics.1997. 20 $0^{\text {th }}$ Edition (International) Prentice hall International Inc.

11. ICMR Bulletin, June 1999. "Increased male responsibility and participation: A key to improving the reproductive health". Vol.26,No.6. p. 59-68.

12. King k Holmes, Per Anders Mardh, P Friederick Sparling. March 1999. "Sexually Transmitted Diseases" - $3^{\text {rd }}$ Edition - McGraw Hill international edition : 1089-132.

13. Scarlatti G.1996 Sep. " Pediatric HIV infection” - Lancet 348(903):863-8.

14. Joycelyn Elders.1998 Aug. "Adolescent pregnancy and sexual abuse" -JAMA Vol.280 No.7. 
15. Freitag - Koontz MJ.1886 Sep. "Prevention of Hepatitis-B and C transmission during pregnancy and the first year of life" . Journal of perinatal and Neonatal nursing.10(2) : 4045.

16. Sheldom H Cheery, Irwin R Merkat.4th Edition 1991. " infections in Pregnancy" Complications of pregnancy - Medical, surgical, gynaecological, psychosocial and perinatal -Williams/Wilkins:302-83.

17. Brabin, Gogate, Karande.1998. " Reproductive tract infections, gynaecological morbidity and HIV seroprevalence among women in Mumbai, India " - Bulletin of WHO. 76(3): 27787.

18. Julie A Mobley, Robert E Mekeown.1998 Apr. "Risk factors for congenital syphilis in infants of women with syphilis in South Carolina" .American Journal of Public Health. Vol.88 No.4.

19. Lyn Finelli, Stuart N Berman.1998."Congenital Syphilis - Bacterial diseases" - Bulletin of WHO. 76(suppl.2):125-8.

20. Margaret J Godley.1996. "STD’s in pregnancy". Medicine group(Journal)Ltd.

21. Obstetrics and Gynaecology Today .1998 March. "Syphilis in Pregnancy" VOl.III No.3

22. Ambrose King, Claude Nicol and P.Rodin.April1980. "Venereal Diseases". $4^{\text {th }}$ Edition.

23. Nicole Woodrow, Ronald $F$ Lamout.1998 Jun. "Bacterial vaginosis : Its importance in Obstetrics" - Hospital Medicine. Vol 59.No.6.

24. Ronald S, Gibbs MD and Richard L Sweet MD.199. "Maternal and fetal infectious disorders". Maternal \& Fetal Medicine. Creasy Resnik $4^{\text {th }}$ Edition - W.B.Saunders.

25. Anantha Narayan R, Jayaram Panicker CK.1996. "Textbook of Microbiology" $5^{\text {th }}$ edition. Orient Longman Publishers.

26. Ratnam SS, K Bhaskar Rao, S Arulkumaran.1996. "Obstetrics and Gynaecology for postgraduates" Vol.2. I Edition . Orient Longman Publishers: 370-84.

27. Hoosen AA,Mohatsoa M. may 1996." Granuloma inguinale in association with pregnancy and HIV infection", International Journal of Obstetrics and Gyanecology,53 (2) :133-8

28. Pritchard, Mac Donald, Gant. Williams Obstetrics. 1985 Edition.(International) : 6227.Appleton -Century -Crofts Prentice hall Publishers.

29. Tibor Nyari, Judith Deak, Elizabeth.1998."Epistudy of Chlamydia trachomatis infection in pregnant women in Hungary"- Sexually transmitted infection.74 :213-15.

30. Mexican Journal of Obstetrics and Gynaecology.1995 Feb. "Hepatitis- B infection in pregnancy - Clinical and prophylactic implications".63:90-5.

31. Brkic S,Jovanovic H.1998 jan-Feb. "Genital herpes with special emphasis on perinatal HSV infection”. Medicinski pregled.5191-2):49-9.

32. K Bhaskar Rao, Ratnam SS, S Arulkumaran.1996. "Obstetrics and Gynaecology for postgraduates" Vol.1. I Edition . Orient Longman Publishers.

33. David C Lagrew, Terrance Gregory.1984 Oct. "Disseminated herpes simplex virus infection in pregnancy". JAMA, Vol.252 : No.15; 2058-9.

34. Brown ZA,Selke S,Zeh J.1997 Aug .21. "Acquisition of HSV during pregnancy". New England Journal of medicine.337(8) : 509-15.

35. Steven G Silverbag, William J Frable. "The uterine cervix" - principles and practice of surgical pathology - II edition Vol.3. Churchill Livingston Publishers : 2343-2409.

36. "Obstetrics and Gynaecology Communications" -1999. "HPV infection in cervical carcinogeneisis" 2:15-22.

37. Harold S Margolis.1998. "Hepatitis-B Virus infection" - Bulletin of WHO. 76 (Suppl 2) :1523 
38. Thakur SK, RM Gupta, MKK Rao. March 1999. "Hepatitis-B carrier- a study of possible routes of acquiring the infection in Army hospital Delhi cantt and AFMC Pune" - Indian Journal of Gastroenterology.Vol.18(suppl-1).

39. Deodhar NS.1998 oct-Dec. "Epidemiology of HIV infection- A critique" - Indian Journal of Community Medicine”. VOl.XXIII No-4.

40. Sharma R. Malik A, Maheswari V.1996 Dec. "Hepatitis-B virus infection in pregnant women and its transmission to infants". Journal of Tropical pediatrics. 42(6): 352-4.

41. Mittal SK, Rao S.Rastogi.1996 Jul-Sep. "Hepatitis-B - Potential of perinatal transmission in India “.Tropical Gastroenterology.17(3):190-2.

42. Gill HH, Majumdar PD, Dhunjibhoy KR.1995 April. "Prevalence of Hepatitis-B e antigen in pregnant women and patients with liver diseases". Journal of the Associations of Physicians of India.43(4):247-8.

43. Adarsh Chopra, BK Chopra, Ramesh k Puri.1996." HBs Ag and Sexually Transmitted Diseases “_ Indian Journal of Dermatology, Venereology and Leprology.62: 89-90.

44. Donald P Kotler.1998 Mar. "HIV in pregnancy - pregnancy and gastrointestinal disorders "Gastroenterology clinics of North America. Vol27.No.1 :268-75.

45. Lokeswr Mr,Nitin shah.1998 oct-Dec. "AIDS in children - perinatal transmission and its prevention",- Asian Journal of pediatric Practice.Vol.2.No.2.: 34-8.

46. Obstetrics and Gynaecology Today.1999 May.Vol.IV.No.5.p.296-303.

47. Peter Riot.Thomas Parran Award Lecture.1999 may. " learning from success - Global priorities for HIV prevention" - Sexually Transmitted Diseases.Vol.26 No 5 ;244-9.

48. Lynne M Mofenson.1999 March ."Short course zidovudine for prevention of perinatal infection". Lancet Vol.353 : 766-7.

49. ICMR Bulletin ,"Children with HIV/AIDS - Challenges and oppourtunities".Vol27 No.12:117-27.

50. Kant S,MS Patel, P Seth. 1998 Jul-Sep. “ HIV seroprevalence among pregnant women residing in selected slums of Delhi” - Indian Journal of Community Medicine. Vol.XXIII No.3 : 116-9.

51. Saple DG, JK Maniar. "AIDS - IADVL Text book and Atlas of Dermatology: Chapter 54,p.1283-99.

52. Lee MH, Hallmark RJ, Frenkel LM.1998 Dec. "Maternal Syphilis and vertical perinatal transmission of HIV type 1 infection"- International Journal of Obstetrics and Gynaecology.63(3) :247-52.

53. Ruth M, Greenblatt, Peter Bacchetti.1999 March. "Lower Genital tract infections among HIV infected and high riskunijfected women".Sexually Transmiteed Diseases. Vol.26 No.3..

54. Valeriane Leroy, Joel Ladner, Marie Nyiraziraje.1998."Effect of HIV 1 infection on pregnancy outcome in women in Kigali, Rwanda 1992-1994" - AIDS, 12:643-50.Lippincott Raven Publishers.

55. Gita Ganguly Mukherjee, Adrya Kumar Datta. 1997 Jun. "AIDS in pregnancy - its ethical and legal issues _Asian Journal of Obstetrics and Gynaecology Practice.Vol.1, No3 :29-32.

56. Vincent T Devita, Samuel Hellman, Steven A Rosenberg.1997. "AIDS- Etiology, diagnosis, treatment and prevention" - $4^{\text {th }}$ Edition- Lippincott Raven Publishers: 167-73.

57. Jiandani CJ.1998 Jul-Aug. "Global strategies for the prevention of HIV transmission from mothers to infants" -AIDS ASIA. 
58. Inaam A Nakchbandi, J Gai Longenecker.1998 May. "A decision analysis of mandatory compared with voluntary HIV testing in pregnant women", Annals of Internal Medicine,VOl.128 No.9 : 760-7.

59. Selections from British MJ.1995 Jul. "Management of Genital Candidiasis - Working group of British society for Medical mycology".Vol11.

60. Mendling W.1998 Apr."Vulvovaginal mycosis" Zeitschrift Fur Arztliche fort bildung und Qualitat sschering.92(3) : 175-9.

61. Petrin D,Delgaty K,Bhatt R,1998 April. "Clinical and microbiological aspects of Trichomonas Vaginalis". Clinical microbiology reviews.11(2) : 300-17.

62. P.Elsner Zurich.EichmannZurich.1996. "Bacterial Vaginosis"- Joachim Martius . STD Advances in Diagnosis and Treatment - Current problems in Dermatology - Vol.24.

63. Paige DM, Augustyn, Adih WK.1998 Mar- Apr. "Bacterial vaginosis and preterm birth - a comprehensive review of the literature ".Journal of Nurse - Midwifery.43(2) :83-9.

64. Ronal F Lamont ,Elizabeth A Hudson.1999. “ A comparison of the use of Papanicolaou stained cervical cytological smears with Gram stained vaginal smears for the diagnosis of bacterial vaginosis in early pregnancy" - International Journal of STD \& AIDS.VOl.10:93-7.

65. Woodrow N, Lamont RF.1998 June . "Bacterial Vaginosis - its importance in Obstetrics".Hospital medicine : 59(6):447-50.

66. Fan S, Liu Z,Chen C.1997 Feb. "Bacterial Vaginosis in pregnant women “.Chinese Journal of Obstetrics and Gynaecology.32(2);84-6.

67. Martinez de Tejada B, Coll O, Deflores M .1998 " Prevalence of Bacterial Vaginosis in an obstetric population of Barcelona “- Medicine clinica 110(6);201-4.

68. Charles H,Liven Good, David E.Soper.1999 March."Comparision of once daily and twice daily dosing oof $0.75 \%$ metronidazole gel in the treatment of bacterial Vaginosis". Sexually Transmitted Diseases.Vol 26.No3.

69. Stray - Pedersen R.1997. “is screening for genital infections in pregnancy necessary?”. Acta Obstetrica et Gynaecologica Scandinavica supplement.164;114-20.

70. Barbara F Atkinson, Jan F Silverman.1998. "Cytological techniques, artefacts and special procedures" -Atlas of difficult diagnosis in cytopathology -1 st edition. W.B. Saunders company.

71. Grace T Mackee.1997 1'st edition."Cytopathology" Mosby Wolfe- Times mirror International publishers Limited:13-63.

72. Peter S stack.1997 Apr. "pap smears" - Post graduate medicine.Vol.101 No.4 ; 207-14.

73. Margaret Stearn, Winifred Gray.1996 Nov. "STDs ad the cervical smear "- Medicine International : 23-6.

74. Sarah K Efwards,Chris sonnex.1998. "Influence of genital infection on cervical cytology"Sexually transmitted infections : $74: 271-3$.

75. Takac, Gorisek.1999. "Chlamydia Trachomatis infection in Women with and without CIN" International Journal of STD \& AIDS .Vol.10: 331-3.

76. Herzberg AJ, Silverman JF.1996 May "Detection of Trichomonas vaginalis in endocervical and ectocervical smears".Diagnostic cytopathology.14(3) : 273-6.

77. AK Jaiswal, S. Banerjee, 2002. "Changing trends in STDs in North Eastern India" Indian Journal of Dermatology, Venereology and leprosy; 68: P 65 - 66.

78. Jeffrey T.Kirchner, David. H. Emmert, January 2000. "STDs in women" Post graduate medicine; Vol 107 / No.I.

79. Arun. C. Inamdar, January 2002. "STDs in pregnancy" IADVL news letter: P 3 - 5. 
80. Sujay Khandpur, Subhav Agrawal, July - Dec 2001. "Clinico-epidemiological profile \& HIV seropositivity of STD patients" Indian Journal of Sexually Transmitted Diseases; Vol 22/No.2: P 62 - 65.

81. Gilbert. GG. Donders, March 2000. "Treatment of sexually transmitted bacterial diseases in pregnant women" Drugs; 69(3): P 477 - 485.

82. K. Siddappa, K.Ravindra, 2001. "SYPHILIS" IADVL Text book and Atlas of Dermatology, Volume II, IInd edition, chapter 53: P 1390 - 1422.

83. PVS Prasad, T. Paari, 2001. "Malignant Syphilis (Lues Maligna) in a HIV infected patient" Indian Journal of Dermatology, Venereology and leprosy; Vol. 167: P 192 - 194.

84. Rangiah PN, 1961. "Syphilis and infancy" Ind. J. Dermatol Venereol; 27 : P 165 - 187.

85. "Chancroid - an update" 2002. IJDVL; 68: P 5 - 9.

86. "Treatment of chlamydia infections in pregnant women" September 2000. Disease management, DRUGS 2000; 60 (3): P 597 - 605. CM Gupta, S. Sanghi, 2001. "Clinical and Bacteriological study of urethral discharge". IJDVL; 67: P 185 - 187.

87. Jack - D. Sobel, 1997. "Vaginitis" New England of Journal of Medicine - Vol 26.

88. "Chlamydia and HSV infections "January 2000. Post graduate medicine - Volume 107/No.1.

89. Tim Schacker, 2000. "Tackling HSV in HIV patients". Herpes virus infections : New Paradigms for a new millennium; ADIS in focus: P 18 - 24.

90. K. Siddappa, July 2002. "HSV infections - Recent developments" What's new? Issue Number 32.

91. K.Pavithran, 2002. "Genital herpes infection in women" How I manage, IJDVL; 68 : P 142.

92. "Warts and pregnancy" 2000. Obstetrics and Gynaecology Times Vol.3 No.1 : P1.

93. Prof. Sarman Singh, December 2001. "Hepatitis - B virus transmissions" AIDS INDIA New letter; P 1 - 4.

94. Arun C. Inamdar, 2000. "Recent aspects - CME - HIV infections" IJDVL; 66: P 285 - 295.

95. "Antiretroviral intervention to reduce MTCT of HIV infection among pregnant women; the Indian experience" Oct - Dec 2002; AIDS update; Vol.7 No.2: P 1 - 8.

96. "Prevalence of HIV infection among high risk groups and STD clinic attenders in Chandigarh; A 7 year study" 2002. Indian Journal of Sexually transmitted Diseases; Vol.23 No.1: P 14-18.

97. NEW ENGLAND JOURNAL OF MEDICINE, 2001. Vol 344: P 164-172.

98. Subhash K Hira,2001. "AIDS -Epidemiology in India" IADVL Text Book and Atlas of Dermatology; Volume H / 2nd Edition, Bhalani publishing house, Mumbai: P 1501 -1503.

99. P.L. Joshi, December 2001. "NACO,s effects to decrease incidence of HIV infection" NEWS LETTER - Third International Conference on AIDS India: P 1-4.

100. Dilip Mathai, December 2001. "HIV/TB - global epidemic" NEWS LETTER - Third International Conference on AIDS India: P 1-4.

101. Yogesh S. Marfatia, Suresh. P. Joshipura, 2001. IADVL Text book and Atlas of Dermatology: Volume II/2nd Edition Bhalani Publishing house, Mumbai:P 1377-1389.

102. "NEWS YOU CAN USE" November 2001.

103. T.Jacob. John, 1998. "The Draft of Summary and Recommendation of national of National Conference of Perinatal HIV \& pediatric AIDS" Abstract book.

104. EGH hyall et al, 2001. "Guidelines for the Management of HIV infection in pregnant women and the prevention of MTCT" BRITISH HIV Association, HIV Medicine (2001) 2: P 314 -334. 
105. "Epidemiology and natural history of HIV - 1 Infection" Oct - Dec 2002 AIDS update Vol 7; No.2; P 1-4.

106. Current Medical science. April - June 2001. Volume 16, No.2.

107. Graham P. Taylor , 1999. "Role of reproductive tract infections / chorioamnionitis in perinatal HIV and pediatric AIDS abstract book.

108. Kaizad Damania, 1999. "Perinatal HIV intervention" National conference on Perinatal HIV \& pediatric AIDS abstract book.

109. Shilpa Merchant, 999. "VCT for National conference on Perinatal HIV \& pediatric AIDS abstract book.

110. K. Pavithran, 2001. "Balanoposthitis, cervicitis and vaginitis" chapter 59 , Volume II/2nd edition IADVL Text Book and Atlas of dermatology: P 1492-1500.

111. Askok. K. Jaiswal. S.S. Vaishampayan, 2001. "Chancroid and Chancroidal ulcers " Chapter 5 , Volume II/ $2^{\text {nd }}$ edition IADVL Text book \& Atlas of Dermatology $1453-1460$.

112. B.S.N. Reddy, 2001. "Donovanosis" chapter 56, Volume II / 2nd Edition/IADVL Text book and Atlas of Dermatology: P 1461 - 1465.

113. Rishi. K.Bhargava,2001. "Viral STDs" Chapter 58,Volume II/ 2nd Edition/ IADVL text book and Atlas of Dermatology: P $1476-1490$.

114. Mellhaney JS Jr, 2001. "STI and teenage sexuality" American Journal of Obestetrics and Gynaecology - 183 (2); P 1476- 1490.

115. Mohan. C.Shendre, Raj Narayanan. R. Tiwari,2002. "Social Risk factors for STDs"IJDVL ; 68: P 25-27.

116. J. Maniar - Paramanik, J. Gokral, 2001. "Chlamydia Trachomatis infection among asymptomatic males in an infertility clinic" IJDVL; 67: P 242 - 245.

117. Sharma RC, Mahajan V.K,July - Dec2001. "Survey and evaluation of facilities available in STD clinics of Himachal Pradesh" Indian Journal of STDs :P 56 -61.

118. Hay PE,Lamon AF , 1994. "Abnormal bacterial colonization of the genital tract and subsequent preterm delivery and late miscarriage" British Medical Journal; 308: P 295 298.

119. Sadhan Kumar Ghosh, 2002. "A study of the present scenario of STD Management in an urban clinic in Calcutta" IJDVL; 68: P 82-83.

120. S. Sherlock, May 2000. "The natural History of Hepatitis - B" JAMA India - The physicians update, Vol 3, No.5 : P 25-29.

121. Narang SS, Bhargava NC, 1964. "Value of Flagyl in the treatment of Trichomoniasis" IJDVL; 30: P 149 -159.

122. Rama Ayyangar MC, 1996. "Trichomoniasis" IJDVL; 32: P 121-131.

123. Joshi BN, Jundre Shailaja, 1980. "Prevalence of Hepatitis - B Antigen / Antibody in patients of Syphilis" IJDVL; 46: P 335 -337.

124. Rishi Bhargava, July - December 2001. "Editorial” Indian Journal of STDs; Vol 22, No.2.

125. Anuradha Khanna, Kalpana Singh, November 2001. "Should pregnant women be screened for neoplasia?" Asian Journal of OBS \& Gynae Practice; Vol-5, No.4.

126. Shantha et al, Feb 2000. "Epidemiology of Cancer of Cervix" JIMA. Vol.98; No.2: P 49 - 51.

127. Roy Chowdhry, Feb 2000. "Cancer of Cervix - Problems and Challenges of the third millennium" JIMA; Vol 98; No.2 : P 39-40.

128. Fungal infections in HIV patients" January - March 2002, Dermanet series; Vol.3 No.1. 

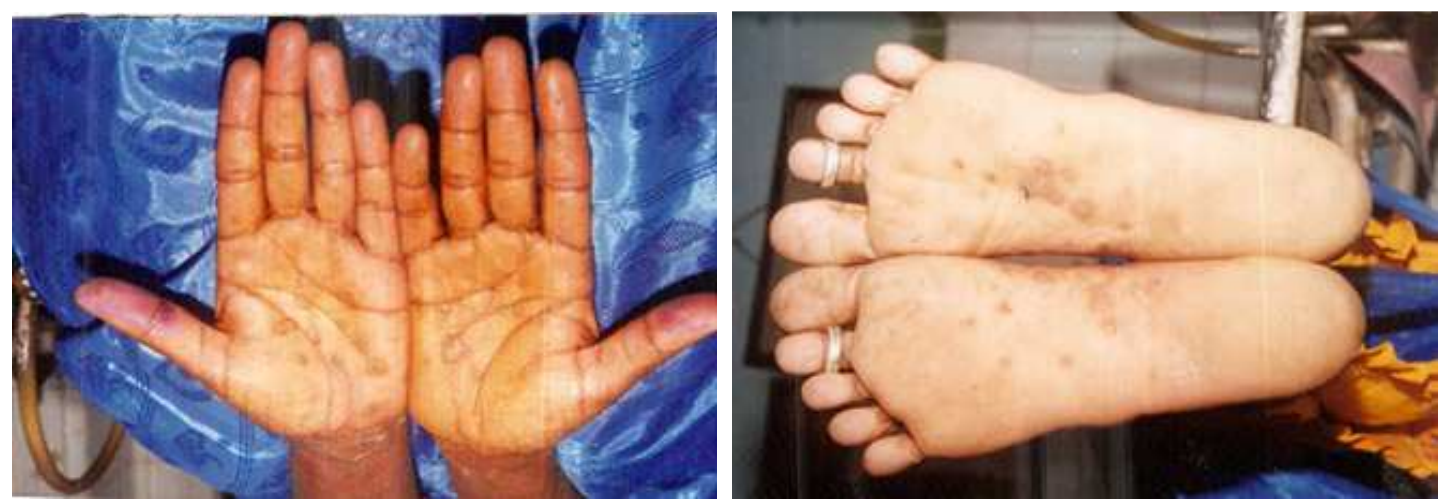

Pic 1 Palmar syphilide Pic 2 Plantar syphilide

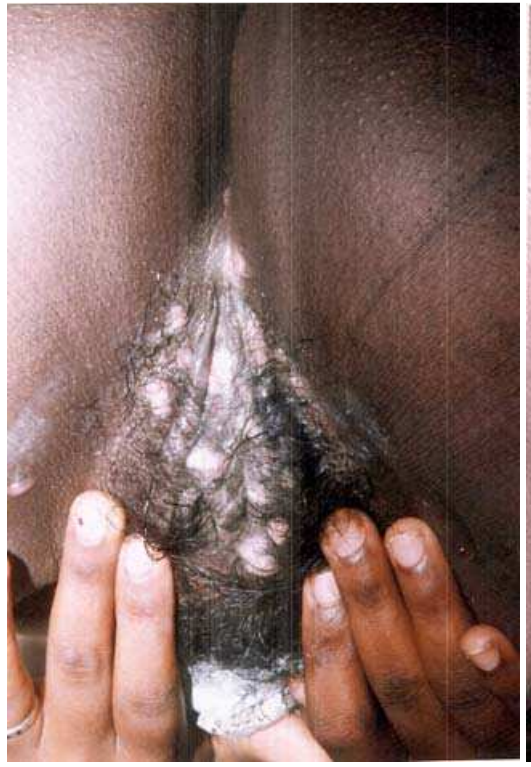

Pic 3 Herpes with candidiasis



Pic 4 Primary chancre 




Pic 5 Vulval warts

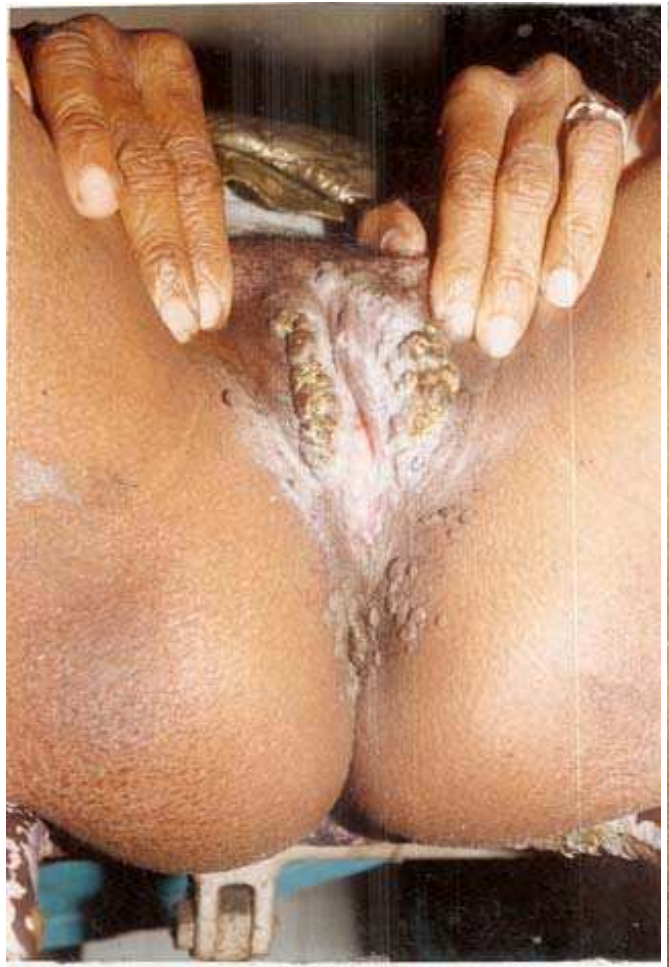

Pic7 Warts with candidiasis

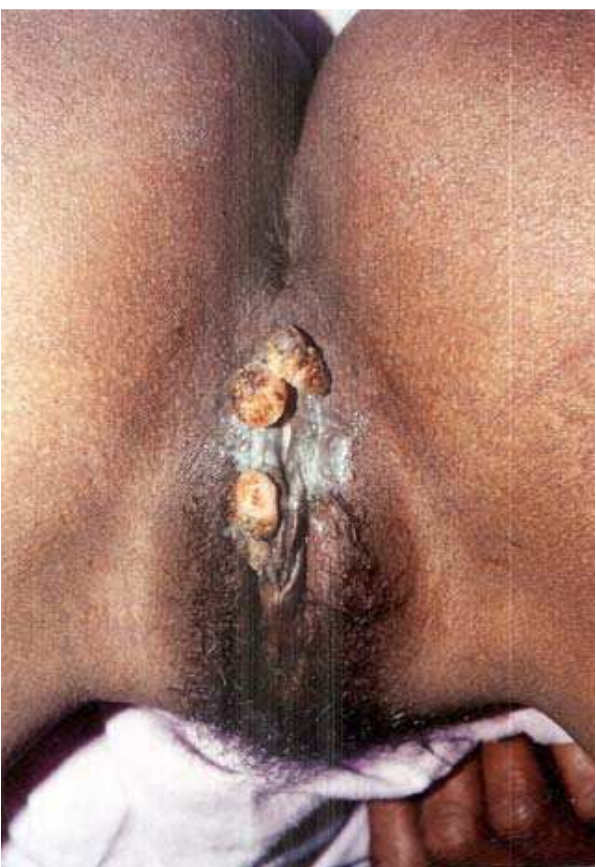

Pic 6 Warts with Trichomoniasis



Pic 8 Molluscum contagiosum 


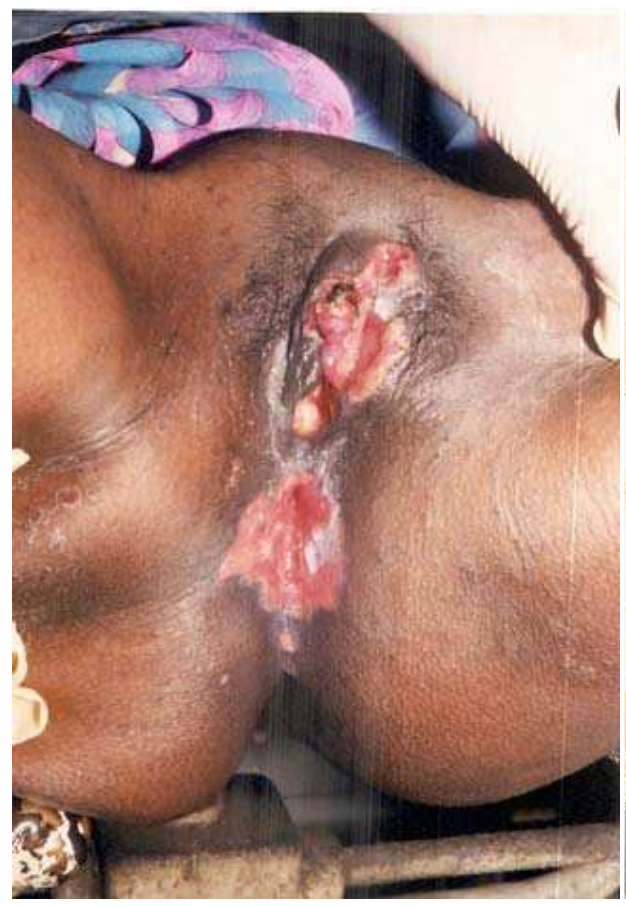

Pic 9 Extensive herpes in HIV

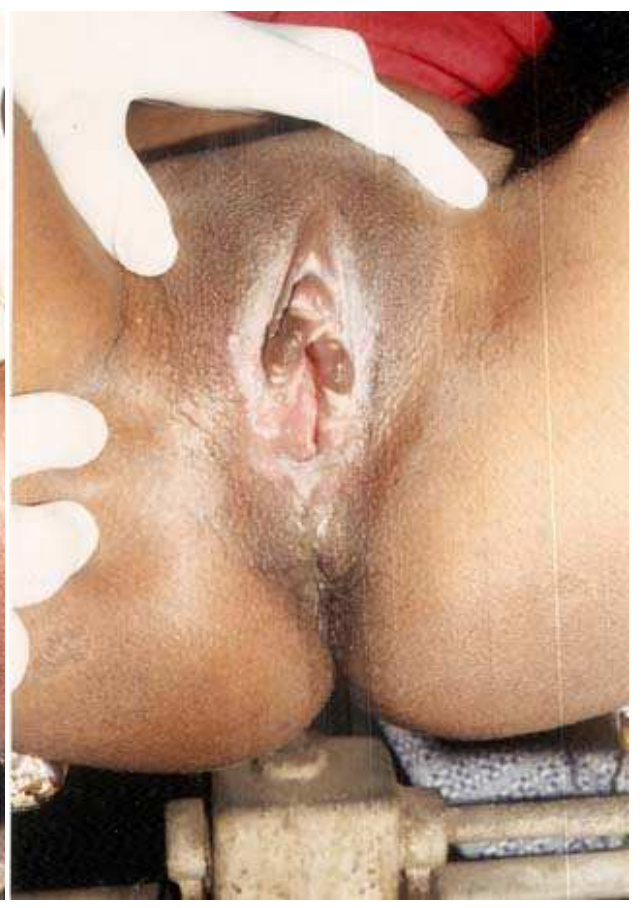

Pic 10 Vulval herpes with candidiasis 